\title{
Text-To-Speech Software: a New Perspective in Learning and Teaching Word Stress, Word Intonation, Pitch Contour, and Fluency of English Reading
}

\author{
Hussein Meihami \\ Department of English Teaching, Ghorveh Branch, Islamic Azad University, Ghory n, Irair
E-mail address: hussein.meihami@yahoo.com \\ When mentioning technology in the language classroom, ${ }^{\prime} \mathrm{e}$ fin 'mpulse is think computer
} technology, almost because computers have so pervade ou a.ily ho workplace, and society contexts. The aim of this experimental research is to inve ugato the effect asing Text-To-Speech Software (TTS), one of Computer Assisted Language Le ning (CALL) reso arces in teaching reading, in different aspects of reading fluency. In this study, w nvestigated paching and learning of Word Stress, Word intonation, Pitch Contour, and Fluency on glish read ng through TTS. It should be stated that comprehension had been worked in the progran $\mathrm{t}$ investigated in the study. The study indicated that word stress; word inton_nitch contour, and fluency had significantly improved by using TTS software.

Keywords: computer assisted langy roning; 1 ading fluency; speech to talk software; teaching reading; text-to-speech

\section{INTRODUCTIC}

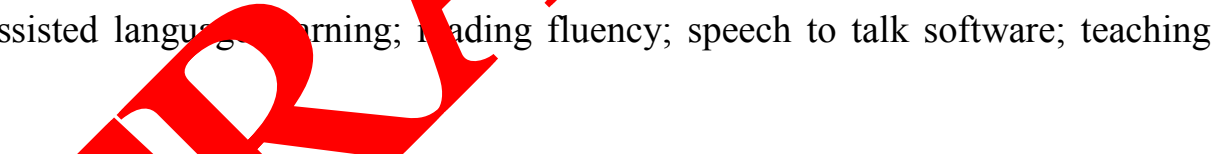

There is a con versial q estion on when technology entering the language classroom. Some like to $\mathrm{vk}^{\mathrm{t}}$ atieo nology first entered language classroom in the $1950 \mathrm{~s}$ and $1960 \mathrm{~s}$ in the form of lans labo atory (Brown, 2007). Institutions hastened to dedicate rooms to the instal aty f mu ape-deck-equipped booths where students gathered to listen to native sp ers 1 bdeling ae drills of the current day's lesson (chapelle, 2005). Often users of lang . able to record their own voice and latter on repeated it to see its problems and to $a$ ulate with their instructors about it. The advent of language labs brought promises of great b akthroughs in language teaching: technology would come to rescue the less effective methods (Brown, 2007). When the personal computers came on the scene in the 1980 s, some pioneers in language teaching thought of it as a salvation for the situation of less effective methods. Once again, this time with a more confidence, pioneers of language teaching thought of the state of art method which was emerged by the computer technology can be used as a relief to the existing complexes in the field of language teaching. Over the changing in century, the computer technology factories started to develop language learning software due to the demand of new language learning importance and new language learning 
preference. The former as Fromkin et al. stated in 2009 is all about speaking English as the glob lingua franca. Due to this fact and spreading English as the world communication more people tended to learn English language. The later, new language preference is all about the change in the way of learning new language. In the world that new technology can be seen in all aspects of human lives then you can not deprive language learning and language teaching of it so computer technology easily and may be by its own self entered the world of language learning. The recent advances in education applications of computer hardware and software have provided a rapidly growing store of resources for language classes.

The computer assisted learning (CALL) are flourishing with such a high speed that it is almost impossible for language instructors to keep up with them and CALLs are always a step ahead. According to Jamieson \& Chapelle 2010 CALL materials are intended to and beneficial for learners, and publishers tend to claim that their materir succeec achieving those goals. Other like Brown 2007 stated that instructors shouldn't he allure computer-based technology fool them into thinking that computers will $\mathrm{p}$ ascally $\mathrm{ke}$ th $\mathrm{Ar}$ students happy and successful. There are also other terms in accord ice an somo s in conflict with the term CALL. Among them we can first man communication (CMC) which was being more widely accepted poner itegrating computer technology into language learning methodology (F, rt, 2005). second most accepted term after CMC is technology-mediated langua (lea g (TML) - As the term speaks for itself, computer is not all technology we can in our ssrooms and there are lots of other technologies that can be used (Kern, 20 $\%$, p.185). In ver simple terms, speech synthesis is the process of making the computer talk Handly, 2008).

Unlike other methods of providing the con ter with voice, such as the digital recording of human speakers, text -to-speech (Th syntb sis systems, which generate speech from text input, have the unique a to gentur speech models, which can be exploited for the provision of talking text fad litio nel, 2003a), the automated generation of exercises with spoken language support (c P sper, 997 ), and the generation of feedback (Sherwood, 1981) and conversa turns Egan and LaRocca, 2000) on demand to unanticipated learner interact ns. Y, , the $u$ of TTS synthesis in Computer-Assisted Language Learning (CAI Mely accepted (Egan and LaRocca, 2000; Sobkowiak, 1998) and t'e numb commercial applications which put together TTS is quite restricted (Hand $y$ ). One possible reason for this is that the suitability and advantages of use TTS synthesis in CALL have not been proven. One way in which this can $\mu$ dchieved hyough evaluation. In this study we have just worked on phonological spects if reading and comprehension wasn't assessed. we investigated the use of TTS in te. ing Word Stress: the stressed syllables in every content words (Fromkin, et al,2009) Word nation the intensity of producing a word, Pitch Contour: The intonation of a ento (Fron et al,2009), and Total Fluency: the relative easiness in reading.

1.1.

CA. applications integrating speech technology have emerged from the general need in language learning and teaching for "self-paced interactive learning environments" which provide "controlled interactive speaking practice outside the classroom" ( Ehsani and Knodt, 1998 , p. 45 ). Though little heard of in CALL until recently, it was identified that TTS synthesis could play a role in responding to this need over twenty five years ago (Sherwood, 1981). Specifically, Sherwood made the observation that typing /editing text is easier than recording voice and that navigating through a textual database is easier than retrieving recorded samples from an audiotape. He also observed that TTS synthesis has the capacity to generate speech models on demand, and that this capacity could be exploited in CALL to 
provide learners with personalized feedback. A decade or so later, the same advantages were again put forward, this time by the technology specialists themselves ( Dutoit, 1997; Keller and Zellner-Keller,2000). They saw TTS synthesis as an "indefatigable substitute native speaker" (Keller and Zeller-Keller, 2000, p.111), which because it is not human is perceived as non-judgmental. It has been suggested that the advantages of TTS synthesis presented above could be exploited in a number of different CALL applications.

Regarding the evaluation of TTS synthesis for use in CALL, different operational contexts often impose different requirements and therefore require different methods of evaluation ( Sparck, Jones and Galliers, 1996). Applications in which TTS synthesis assumes the role of a reading machine include: talking dictionaries, talking texts and dictations.

A talking dictionary is an electronic dictionary which integrates either digita of human speakers or speech synthesis for the oral presentation of dictionar entries. experimental pronunciation tutor SAFexo, a module of the CA LL system SA) (Syster) d'Apprentissage du FRANcais; Hamel, 1998, 2003a), focuses on this of p ice. In example of a CA LL application that uses TTS synthesis in the teachin of prody is cier et al.'s (2000) prosodic tutor for Breton. Examples of spoken a. gu syste ns which integrate TTS synthesis that are currently being developed fo use anguag, learning include the Let's Go Spoken Dialogue System (SDS) (Raux Eskenazi, and SCILL (Spoken Conversational Interaction for Language Learning yste Seneff e al., 2004 ).

Our review of the literature reveals that very "form eyaluations of TTS synthesis for the specific purposes of CA LL have oeen con ducted stratil et al., 1987a; Stratil et al., 1987b; Cohen, 1993 ; Santiago- Or 1 a, 1999; Hincks , 2002 ). Moreover, general purpose tools for the evaluation of speed synthesis ystems such as the ITU-T Overall Quality Test (Schmidt-Nielsen, 1995; van Be. ien ar d van Heuven , 1997 ) which is exploited in the Blizzard Challenge ( Be 2005; Drack and Tokuda, 2005 ), a speech synthesis comparative evaluation campaign, do dyess some of the criteria which are believed to be important for language arning applications, such as naturalness, expressiveness and register. Rega … valuat $\mathrm{n} s$ of TTS synthesis for the specific purposes of CALL, identification of pot tial ben its TTS could bring to CALL could be considered to fulfill the fur tio f carch evaluation. However, regarding the next stage of evaluation ree smmende by Handley and Hamel (2005), namely technology evaluation, only one $\mathrm{c}$ of an eva cion of the adequacy of TTS for use in CALL was found in the literatu. In is study, we are going to investigate different effect TTS on reading fluency Among the atyportant aspects we can mention Word Stress, Word Intonation, $\mathrm{P} ;$ ch Coi sur, and Total Fluency.

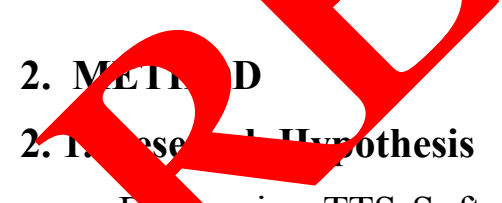

D using TTS Software for intermediate EFL students improve their reading quality such as, W d Stress, Word Intonation, Pitch Contour, and Fluency? 


\section{2. Participants}

For the purpose of this study, Azad University of Ghorveh was chosen as the context due to this university facility in computer assisted language learning (CALL). This university has equipped with a big language laboratory with 40 computers. On these computers there have been different CALL material installed.

A total of 83 students of accounting all male and ranging in age from 22 to 25 were recruited to participate in an English Reading Program (ERP) as summer free credit course. Prior to course start, a placement test was conducted to rank students. It should be stated that scoring procedure was done discretely in which scoring was done based on the scales that pertain to Word Stress (WS), Word Intonation (WI), Pitch Contour (PC), and Total Flumcy.

More information would be prepared in material section about this scoriy $\mathrm{p}$ proce Based on the achieved result 46 students were ranked as intermediate, 22 ydents $w$ ranked as high intermediate, and 14 students were ranked as low interpedia reading based on the scales have been mentioned. A questionnaire ther was held "nd out about students current English program and English exposure.

The results showed that 10 out of 46 students were studyin En. in son English institutes. For the purpose of removing intervening factors, the 10 stud wer put away. Finally 36 students of accounting were entered the CALL En $1 \mathrm{i}$

\section{3. Materials}

Fig. 1 shows the IVONA soft ware.

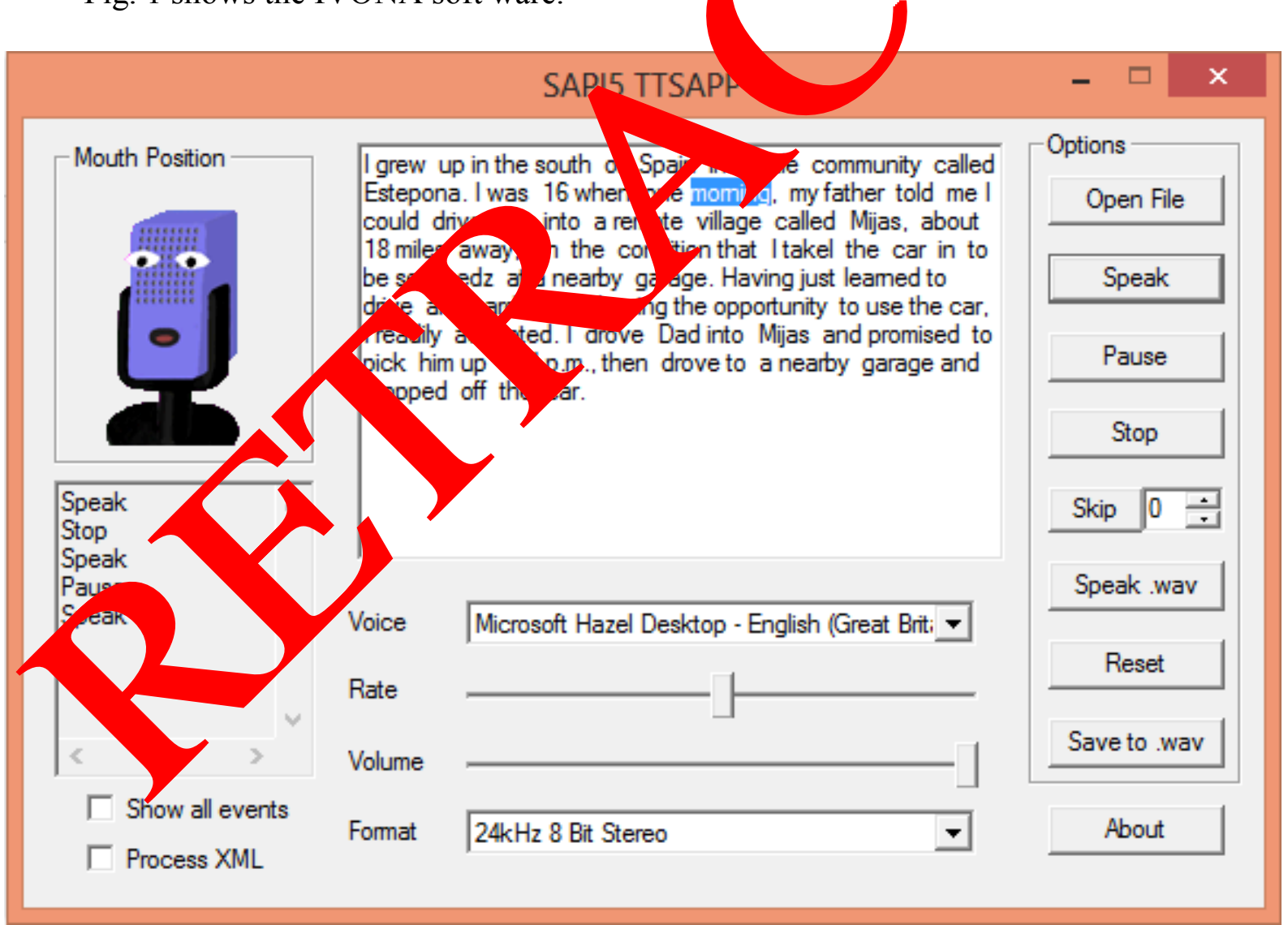

Fig. 1. IVONA Software. 
IVONA UK Brain 1.4.21 was used in this research study. This TTS software is among the newest brand of converting text to speech without any limitation in the length of the texts. It is also providing students with four voice two with British accent and two with American accent. The program also has different rates of speaking production. Due to the level of the students we selected $24 \mathrm{KHz} 16$ Bit Stereo.

This TTS software gives the facility of copying any text in it to be produced in oral form. So we decided to work on Select Reading Intermediate by Linda Lee and Erik Gundersen. Students of the TTS class were given IVONA UK Brain software and Select Reading Intermediate PDF to install them on their personal computers for further activities and exercises. We also used a discrete test of reading to rank students. It is a quite comprehensive test which was rated by a quite comprehensive reading scales ard stress, word intonation, pitch contour, and total fluency. Table one illustrates th se scales.

Table 1. Guideline for Assigning Reading Rating.

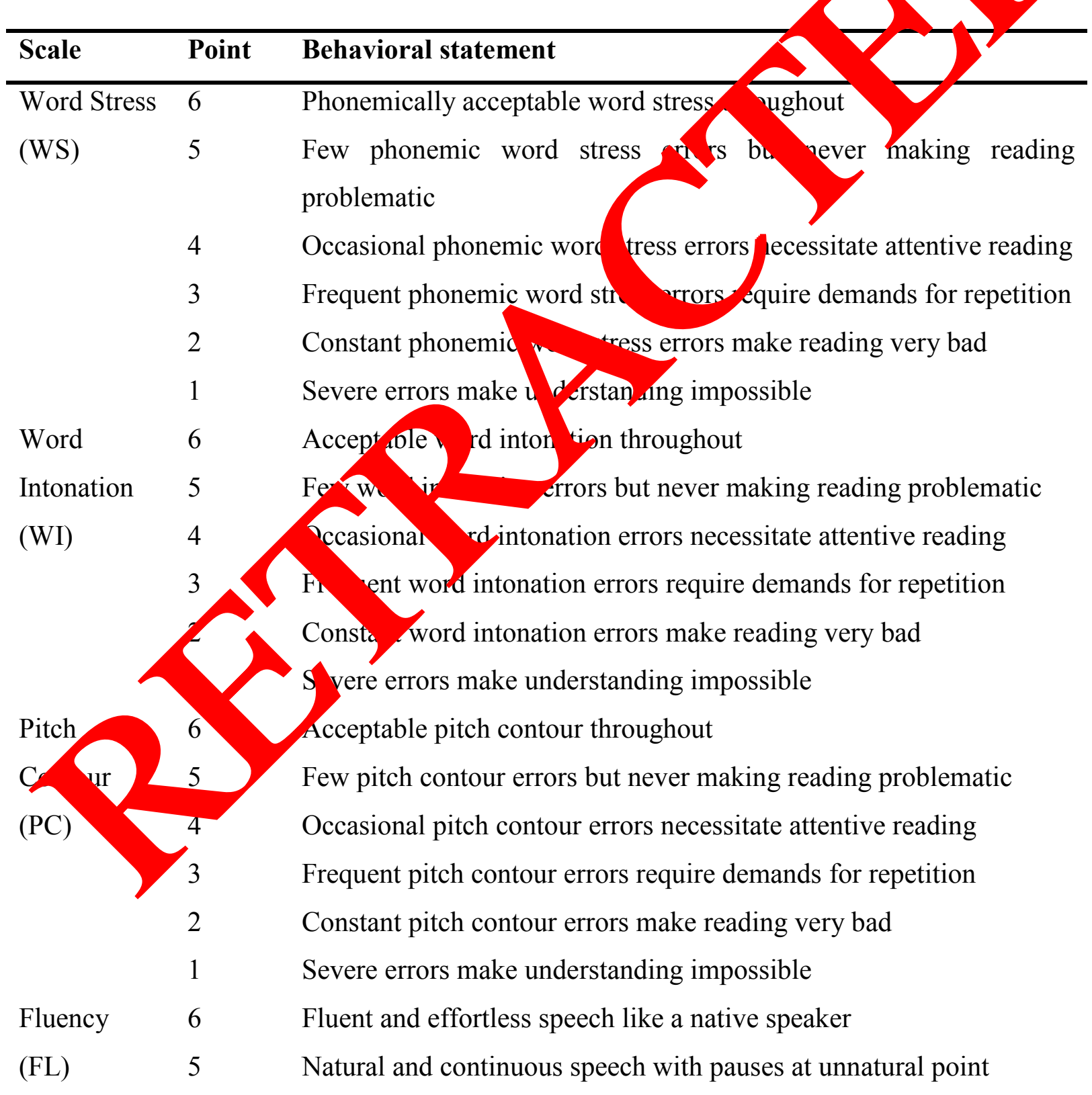




\begin{tabular}{ll}
\hline 4 & Fluent speech with occasional problems \\
3 & Frequent problems hinder fluency and demand greater effort \\
2 & Slow speech, hesitant, and sometimes silent \\
1 & Virtually unable to make connected sentences \\
\hline
\end{tabular}

Table 2 shows the weighting of each point. To obtain a reader total fluency score, the rating on each of the four scales-averaged for the three teachers- are transformed into values in the weighting table.

Table 2. Weighting Table.

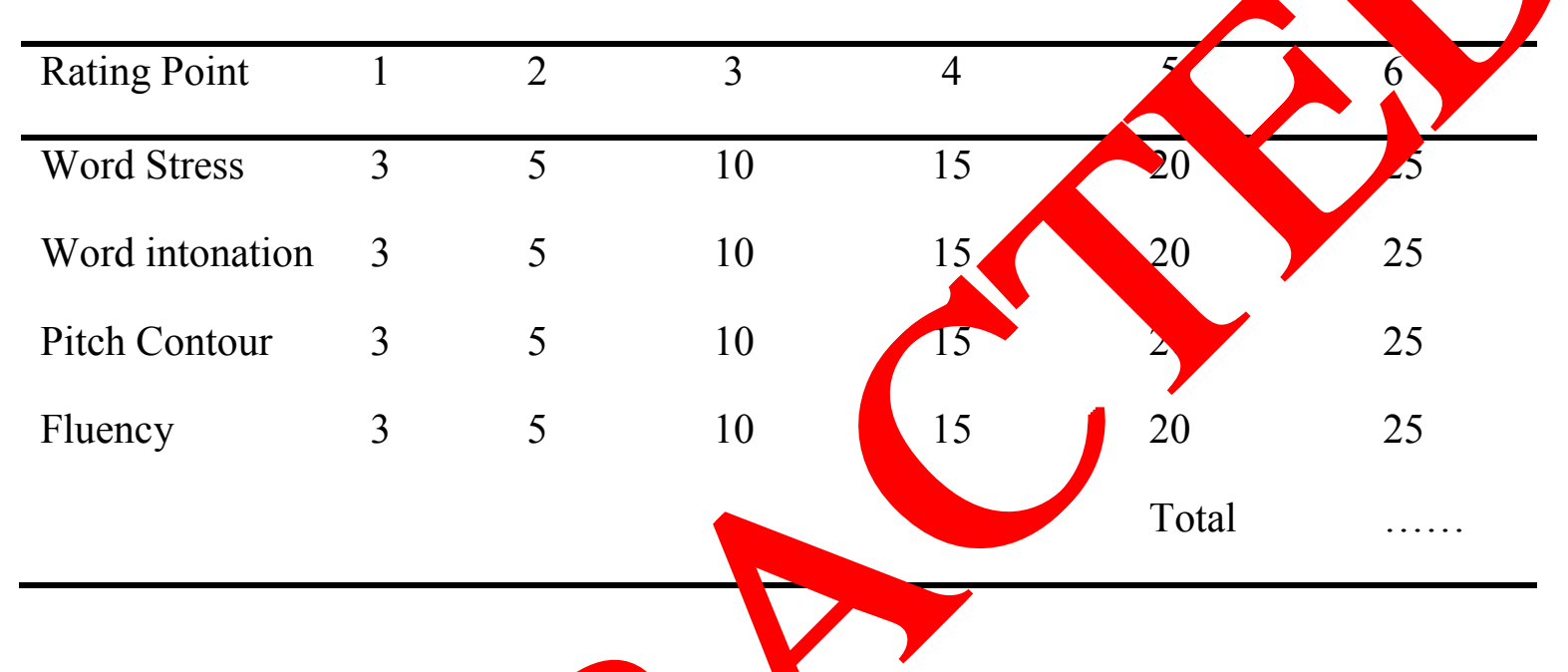

Suppose, for instance, that a ader $r$ eives three in word stress, four in word intonation, four in pitch conte nd th ee in Flu ncy. These ratings are worth a score of 50:

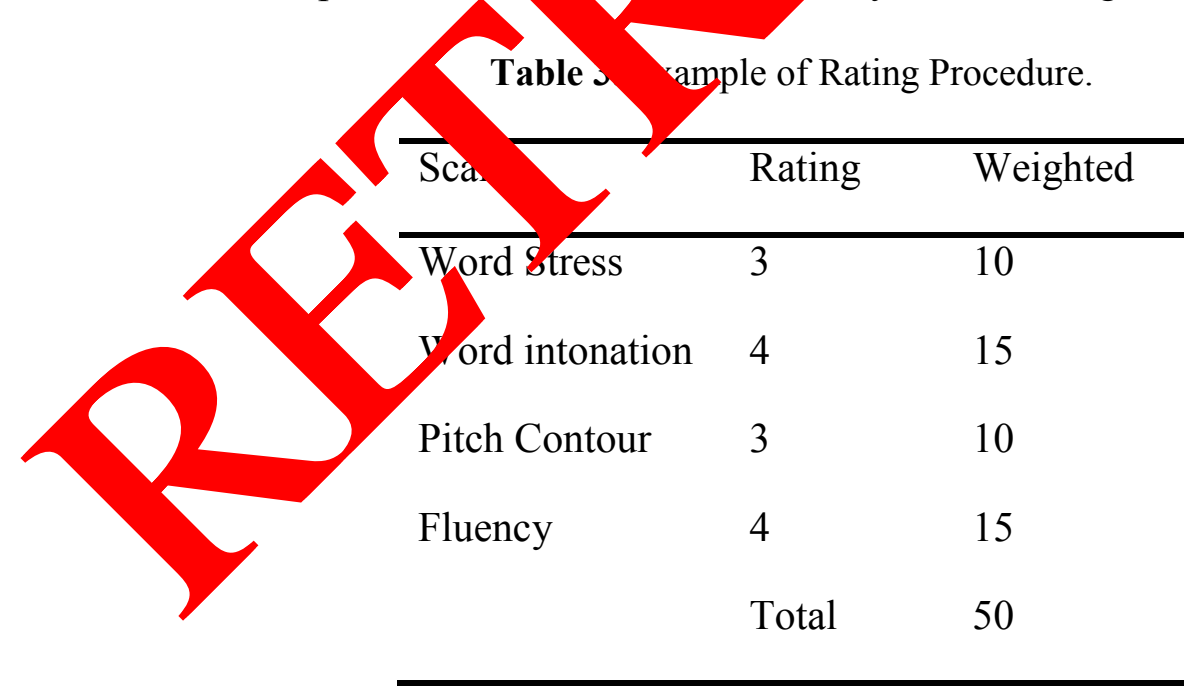

For the final thing here to mention, we used SPSS version 16 to analyze data. 


\section{4. Procedure}

The study was conducted in a period of three months in 2012 summer. The program was divided into two sections. A-one-month class period-July 2012- for making students familiar with (1) different aspects of English reading features such as Word Stress, Word Intonation, Pitch Contour, and Fluency; for the purpose of this students went through an intensive instruction, (2) instruction on how to use CALL materials and specifically IVONA Software. During this one month period students participated in 12 sessions. Then in a-twomonth period, August and September 2012, they were starting English Reading Course.

The program was 24 sessions, three days a week. From the very beginning of the course TTS Software was used in TTS class for the purpose of teaching English reading; brever, the control group went through an ordinary method of teacher reading a stua repetition. In TTS class, each and every student had a computer in front himself. 1 procedure of TTS class was quite interesting in which for each unit of the Felec ading $t$ teacher read it just for once and then the text was copied into IVON A and stuc y re required work on it. Students in TTS class were asked to work differ aspe and features, WS, WI, PC, and FL, as they were instructed in the earli clo on the cer class, the control one, the teacher read the text and then students repe ted it and an stadents were asked to ask about the features.

Then students in both classes were asked to wor 1 som xercises that had been prepared for the purpose of examining students' know ago on word $\mathrm{s}$, Word Intonation, Pitch Contour, and Fluency. In both classes the s Idents' voice wa recorded for weekly progress examining of students by teachers. After ch session, students in TTS class were asked to work on the text at home on their person computer. Students in control group were also required to work on the text base- on what med in the class. At the end of the program another test was conducted bas procedure which the placement test had been done. Students were given a text to read nd anm cacher rated them based on the Table 1 Guideline for Assigning Reading Dating. Th reasol for the rating by three teachers was to be assured of reliability of the cest. pee aga it should be stated that comprehension of reading wasn't assessed in thi

\section{RESULT}

For obtaing the result in ased MANOVA. Table 4. shows the achieved result in this study. Acco g to , TTS class is significant in all English reading features, word stress $\mathrm{p}=$ .008 ; word int on $\mathrm{p}=06$; pitch contour $\mathrm{p}=.002$; and fluency $\mathrm{p}=.000$. this amount of $\mathrm{p}$ in thre featu. show that the difference between TTS class and the control class is quite

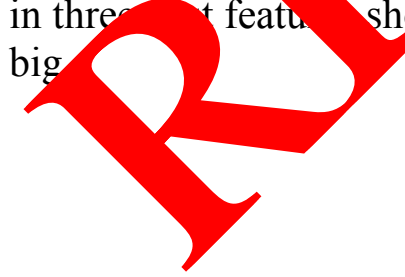


Table 4. Comparison between TTS Class \& Control Class in WS, WI, PC, and FL.

\begin{tabular}{|c|c|c|c|c|c|}
\hline Variable & Mean & SD & $\mathrm{t}$ & $\mathrm{df}$ & $\mathrm{p}$ \\
\hline Word Stress & & & 7.81 & 1 & .008 \\
\hline TTS Class & 16.11 & 5.01 & & & \\
\hline Control Class & 11.83 & 4.11 & & & \\
\hline Word Intonation & & & 8.59 & 1 & .006 \\
\hline TTS Class & 15.16 & 6.5 & & & \\
\hline Control Class & 9.88 & 4.01 & & & \\
\hline Pitch Contour & & & 11.76 & 1 & \\
\hline TTS Class & 16.66 & 4.2 & & & \\
\hline Control Class & 11.66 & 4.53 & & & \\
\hline Fluency & & & 34 & & \\
\hline TTS Class & 18.33 & 3.42 & & & \\
\hline Control Class & 11.66 & 3.42 & & & \\
\hline
\end{tabular}

Inspection of the means indicates th average word Stress scores for TTS class (16.11) is significantly higher than the mea sco control class (11.83). The difference between the mean in TTS \& Control class fo Nord stress is 4.28 that clearly indicates the significance of WS learning by ta of IVC VA software. The same interpretation is true about Word Intonation learni Why TTS c ss mean average of WI is 15.16, the mean average of WI is 9.88 the sho WI learning through INOVA. Based on the achieved statistics the $p$ ean scor Pitch Contour is 16.66 that in comparison with the mean average of PC 10 ontrol cla 1.66 is quite high. There is also 6.67 differences between Fluency in TTS 18.33 and Control class 11.66 that significantly shows the better performa ce in TTS c, All in all the amount of differences in the four reading features indi te the onfirmation of the hypotheses. On the comparison of TTS \& Control class on Wor re $\mathrm{p}=.8$, Word Intonation $\mathrm{p}=.006$, Pitch Contour $\mathrm{p}=.002$, and Fluency $\mathrm{p}=.00 \mathrm{n}$ it is tal $\mathrm{c}$ car that using CALL material in improving reading features is pros crou nd suc al.

\section{Cu Luninen}

The csults of the present study support the hypothesis that CALL materials has a significant effects on Fluency features like word stress, word intonation, pitch contour, and fluency. It was found that gains in knowledge of four aspects of Reading (WS, WI, PC, and FL) tended to be larger with the use of CALL in the classrooms. At on encounter, the participants demonstrated large gains in knowledge of reading fluency, indicating that for intermediate using TTS software can increased their Total Fluency. On the whole, in this study it was cleared that Total Fluency which is a combination of reading features such as word stress, word intonation, pitch contour, and fluency could be significantly improved by 
using TTS software in reading classes. The very rational reason for this happening is that when students have TTS in their personal computers at home they can easily access to a powerful source for learning how to read English texts correctly, so in their spare time and very easily they use it and take advantage of it. On the other hand, in the other class students don't have such a facility and should just learn through class and the teacher is the first and final resource for them.

Overall, the results show that word stress and word intonation aspects of reading were benefited the most from using TTS in classroom, confirming Sherwood 1981results. The results also are in accordance with the previous done researches. (Seneff et al.2004; Hamel, 1998, 2003a).

It is important to note that in this study comprehension of reading was not a considered. Further research examining Reading Comprehension in CALL cla ses should done to find out about using CALL in Reading Comprehension improvements.

What should be considered language planners and teachers is to us ALL teachi $g$ reading features, Word Stress, Word Intonation, Pitch Contour, and $\mathrm{F}^{1}$ ency impr otal fluency of English reading and to use CALL in classrooms till to varta of both learning language and language and the pedagogical context of th

\section{References}

[1] Auralog, (2002). Talk to me: the conversation $n$ thod (French). (Version 3.5) from Auralog <http://www.auralog.fr>.

[2] Beutnagel, M., Conkie, A., Schroeter, J Stylianou, dal, A., (1999). The AT\&T next-gen TTS system. In: Proceedings on int Meeting of the ASA, EAA, and DAGA. Berlin, Germany.

[3] Black, A., Lenzo, K., (2000). d dom in synthesis. In: Proceedings of the ICSLP, Beijing, China.

[4] Campbell, N., Black, and the selection of source units for concatenative synth is. In: van nten, J., Sproat, R., Olive, J., Hirschberg, J. (Eds.), Progress in Spee $n \mathrm{~S}$, hesis. Spn ger-Verlag, London, pp. 279-292.

[5] Campbell, N Aamza, h öge, H., Tao, J., Bailly, G., (2006). Special section on expressiv speed synthesis, EEE Transactions on Audio, Speech and Language Process. 14(4).

[6] Chamlle, C., 001a) Innovative language learning: achieving the vision. $\operatorname{ReCALL}$

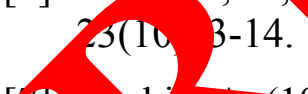

[1] mo of ASA, EAA, and DAGA. Berlin. Germany.

[8] de Pijp , J., (1997). High-quality message-to-speech generation in a practical application. In: van Santen, J., Sproat, R., Olive, J., Hirschberg, J. (Eds.), Progress in Speech Synthesis. Springer Verlag, London, pp. 575-588.

[9] Ehsani, B.K., Knodt, E., (1998). Speech technology in computer-aided language learning: strengths and limitations of a new CALL paradigm. Language Learning \& Technology 2 (1), 45-60, Retrieved January 31, 2005, from $<$ http://lit.msu.edu/vol2num1/article3/> . 
[10] Francis, A., Nusbaum, H., (1999). Evaluating the quality of synthetic speech. In: Gardner-Bonneau, D. (Ed.), Human Factors and Voice Interactive Systems. Kluwer Academic Publishers, Boston, pp. 63-67.

[11] Handley, Z., (2006). Evaluating Text-To-Speech (TTS) Synthesis for use in ComputerAssisted Language Learning (CALL). Unpublished Doc-toral Thesis. The University of Manchester.

[12] Henton, C., (2002). Challenges and rewards in using parametric or concatenative speech synthesis. International Journal of Speech Technology 5, 117-131.

[13] Huang, X., Acero, X., Hon, H.-W., (2001). Spoken Language Processing: A Theory, Algorithm, and System Development. Prentice Hall, Upper Saddle kiver, Ne Jersey.

[14] Keller, E., Zellner-Keller, B., (2000). Speech synthesis in language earning: and opportunities. Procs. InSTIL. University of Abertay Dundee Dunde Englà 109-116.

[15] Multitel, (2005). eLite Documentation. Retrieved from $<\mathrm{b}$ : ://www.i titel.be/TTS/layout.php?page=eLite_doc $>$.

[16] Polkosky, M., Lewis, J., (2003). Expanding the M $D$ revelop evaluation of the MOS-R and MOS-X. Internat onal Journal of S eech Technology 6 , 161-182.

[17] Raux, A., Eskenazi, M., (2004). Using task-oric d spoker dialogues for language learning: Potential, practical applica na chan Delmonte, R., Delcloque, P., Tonelli, S.(Eds.), Proceedings of th Italy, pp. 147-150.

[18] Santiago-Oriola, C., (1999) synthe in a computerized dictation exercise. In: Proceedings of EUROSP $\mathrm{CH}^{\prime}$, , Vol. 1 Sudapest, pp. 191-194.

[19] Schroeter, J., Conkie Sy A., suatnagel, M., Juka, M., Strom, V., Kim, M.-J., Kang, H.-G., Kapy w, D., (20 Aperspective on the next challenges for TTS research. In: Pr ce of of the 2002 Workshop on Speech Synthesis, Santa Monica, Cal oi ia, pp. 1-214.

[20] Seneff, S, Wan C., Zhan, J., (2004). Spoken conversational interaction for language learnim : P oceed ngs of the InSTIL/ICALL 2004 - NLP and Speech Technologies in Langua earnin, Systems, Venice, Italy, pp. 151-154.

[217 Spar Jones, Galliers, J. R., (1996). Evaluating Natural Language Processing vst An nalysis and Review. Springer, London.

[22] St M., Weston, G., Burkhardt, D., (1987b). Exploration of foreign language speech synt s. Literary and Linguistic Computing 2 (2), 116-119.

[23] TMA Associates, 2003. Nuance: US English. Retrieved from $<$ http://www.tmaa.com/tts/Nuance_USEng.htm $>$. 